\title{
$\begin{aligned} & \text { XVII Simpósio Brasileiro } \\ & \text { de Geografia Fisica Aplicada }\end{aligned}$
$\begin{aligned} & \text { I Congresso Nacional } \\ & \text { de Geografia Física }\end{aligned}$
}

\section{INTEGRAÇÃO DOS ELEMENTOS GEOMORFOLÓGICAS E PEDOLÓGICOS EM BOQUEIRÃO (SOBRAL, CE)}

\author{
José Falcão Sobrinho $^{(\mathrm{a})}$, Cleire Lima da Costa Falcão ${ }^{(\mathrm{b})}$, Marcos Venicios Ribeiro Mendes ${ }^{(\mathrm{c})}$, \\ Ana Mesquita Paiva ${ }^{(d)}$ \\ (a) Orientador, Universidade Estadual Vale do Acaraú- UVA, Email: falcao.sobral@ gmail.com \\ (b) Docente, Universidade Estadual do Ceará- UECE, Email: cleirefalcao@ gmail.com \\ (c) Discente, Universidade Estadual Vale do Acaraú- UVA, Email: marcos.venicios10@ hotmail.com \\ (d) Discente Universidade Estadual Vale do Acaraú- UVA, Email: aninha-mp1@ @otmail.com
}

\section{EIXO: SOLOS E PAISAGEM}

\begin{abstract}
Resumo:
O trabalho descreve a relação pedogeomorfológica da comunidade de Boqueirão, situada na cidade de Sobral, no Estado do Ceará. A metodologia adotada consta de pesquisa bibliográfica direcionada e associada às observações de campo, seguindo em outra etapa com as análises dos elementos geomorfológicos, tendo como base a dinâmica do relevo e dos recursos naturais, buscando uma análise detalhada dos aspectos pedológicos da região. Os resultados obtidos mostram que a compartimentação geomorfológica identificada na área de estudo apresenta-se significativas em termos da realidade do semiárido a da pediplanação oriunda da integração entre as vertentes dos Maciços Residuais de Meruoca e Superfície Sertaneja da região de Sobral, constando os solos, Argissolos, Neossolos Litólicos e Neossolos Flúvicos. Pode-se afirmar que as características observadas englobam especificidades que merecem um aprofundamento detalhados sobre a dinâmica do ambiente local.
\end{abstract}

Palavras chave: Integração. Geomorfologia. Solos

\section{Introdução}

A Geomorfologia é um ramo da Geografia física que estuda as formas de relevo, em seus processos exógenos e endógenos quanto à sua origem e evolução. $\mathrm{O}$ estudo geomorfológico analisa dois fatores modificadores de paisagem, os que modelam (climas antigos e atuais, vegetação e solos) e os formadores estruturais de relevo (tectônica e a geologia). Christofoletti, (1980) simplifica essa ideia ao destacar que a Geomorfologia estuda as características morfológicas, as bases litológicas e os processos modeladores e controladores do relevo.

Sabendo que a pedologia é responsável por caracterizar os tipos de solos, que estão inteiramente interligados e que afirma que o solo é um corpo complexo, cuja origem e desenvolvimento são determinados pelos seus fatores de formação (Departamento de Solos, da UFV, 2005), dentre eles o material de origem, que é geralmente um material sólido, rochoso, intemperizado que vai se transformando em solo, solto e incoerente. Considerando o aumento da demanda do conteúdo geomorfológico em projetos ligados aos diversos tipos de planejamentos que visam contribuir com 
projetos dos órgãos públicos, tanto em escalas locais como regionais. Dessa forma, o presente estudo objetivo contribuir com o conhecimento da constituição geomorfológica e pedológica e respectiva dinâmica na comunidade de Boqueirão, situada na área semiárida do município de Sobral/ CE, posicionada nas coordenadas geográficas $3^{\circ} 39^{\prime} 08,37^{\prime}$ 'S e $40^{\circ} 25^{\prime} 16,66^{\prime \prime} \mathrm{O}$, entre a depressão sertaneja e os maciços residuais da Serra da Meruoca, caracterizada por pediplanação.

A pesquisa foi desenvolvida com o apoio do Laboratório de Pedologia e Processos Erosivos de Estudos Geográficos- LAPPEGEO, da Universidade Estadual Vale do Acaraú- UVA.

\section{Metodologia}

A metodologia adotada na pesquisa parte de sistematização bibliográfica do entendimento dos fatores de formação do solo e sua relação com a geomorfologia, destacamos as teorias gerais e a geomorfologia especifica da área de estudo, com ênfase numa abordagem sistêmica que parte do solo e de seus elementos que dão suporte a evolução geomorfológica e uma análise da paisagem visando abstrair a conexão de seus elementos. Na oportunidade foram realizadas atividades de campo como preponderante as observações e averiguação do fenômeno pedogeomorfológico observado na área da pesquisa, além de série de consultas a plataforma do software Google Earth.

Em relação ao contexto pedológico, temos a caracterização dos solos, ao qual encontramos três tipos de solos a saber: argissolos vermelho-amarelo, neossolos litolicos e neossolos flúvicos, diante dessas informações recorremos ao manual de Levantamento Exploratório - Reconhecimento de Solos do Estado do Ceará - Vol. 1 (MA. SUDENE, 1973) e classificados conforme nomenclatura da EMBRAPA SOLOS (1999). Desta forma, foi desenvolvida a pesquisa a fim de conceituar e discorrer acerca sobre a relaçao pedogeomorfológica, dando assim base teórica e sólida para o entendimento do objeto em estudo, bem como o trabalho de campo realizado subsidiou as observações dos processos e dinâmica da paisagem nas compartimentações geomorfológicas elencadas.

Por fim, ressaltamos a importância das observações sobre as formas e processos registrados em fotografia que estão inseridas no presente trabalho.

\section{Resultados e Discussão}

A região de Boqueirão encontra-se numa transição geomorfológica entre Maciços Residuais e Superfícies Sertanejas originadas da pediplanação. De acordo com RADAMBRASIL (1981) os maciços exibem conjunto de relevos montanhosos compartimentados em blocos isolados, 


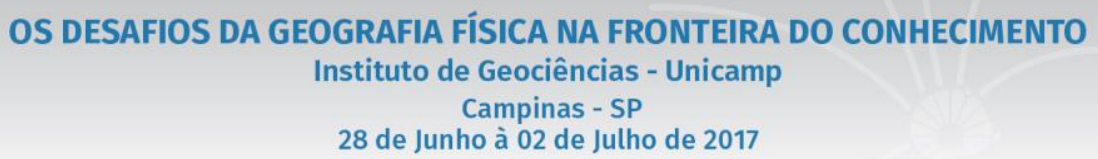

separados entre si pelas superfícies sertanejas e vertentes de barlavento voltadas para leste com alto índice de precipitação pluviométrica e de chuvas orográficas. Ainda nesse sentido, SOUZA (2006) afirma que os maciços residuais se situam entre altitudes a de 650-700 m, apresentando relevo com anatomia em forma de topos convexos e aguçados, por vezes caracterizando-se com interflúvios dotados de declives mais suaves e vales mediana a fortemente profundos.

De acordo ainda com este autor, as depressões semiáridas são superfícies embutidas entre níveis de planaltos sedimentares ou cristalinos, com altitudes abaixo de 400m e com forte diversificação litológica amplamente submetida às condições semiáridas quentes, com forte irregularidade pluviométrica, rede fluviométrica densa, fraca a medianamente entalhada com canais dotados de intermitência sazonal, mosaico de solos associados, sendo comum a presença de solos rasos na superfície sertaneja, bem como os afloramentos rochosos e solos pedregosos, extensivamente recobertos por caatingas arbustiva aberta, onde apresenta uma variedade de padrões fisionômicos e florísticos e de diferentes níveis de degradação em que o uso atual predominante é de atividades agropecuárias e de silvicultura. Logo em seguida a figura 1 nos reforça esse entendimento.

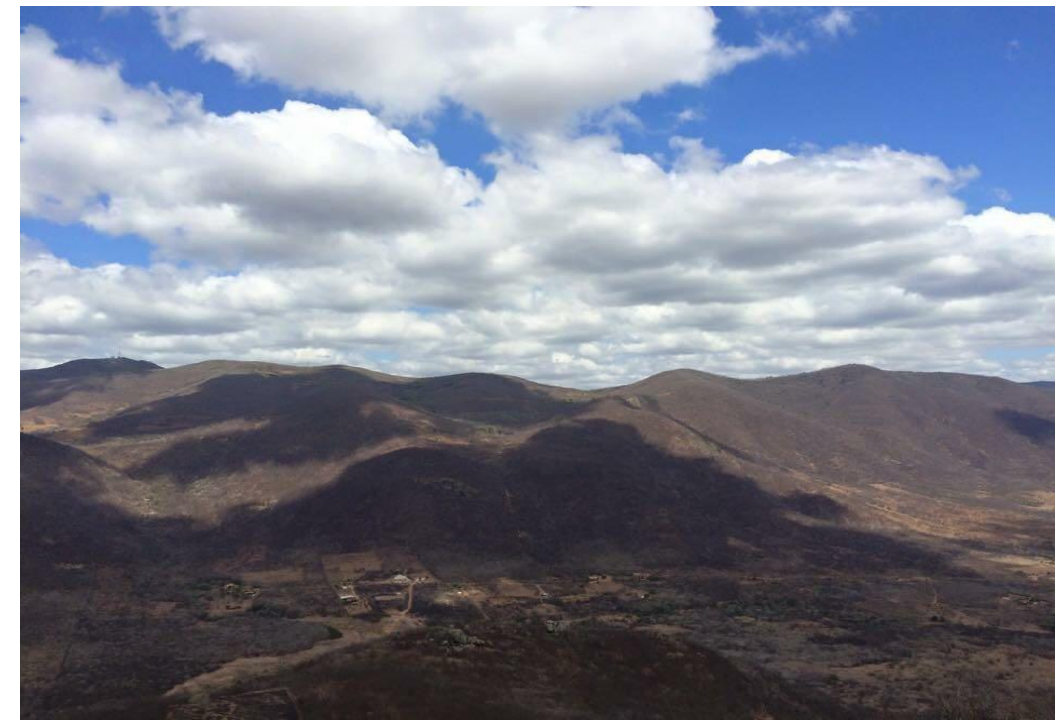

Figura 01. Interação de Maciços Residuais e Depressão Semiárida no Boqueirão. Fonte: Francivanda Dias (2015

Destacamos que a comunidade de Boqueirão, ao mesmo tempo que vivencia uma proximidade com a natureza do semiárido, desenvolve atividades agrícolas sobre os diversos tipos de solos presentes, sobretudo os Argissolos, Neossolos Litólicos e Neossolos Flúvicos aí predominantes. Ainda nesse sentido 


\section{OS DESAFIOS DA GEOGRAFIA FÍSICA NA FRONTEIRA DO CONHECIMENTO \\ Instituto de Geociências - Unicamp \\ Campinas - SP \\ 28 de Junho à 02 de Julho de 2017}

LIMA, E. C. (2007) aponta que a diversidade de tipos de solos é causada por alguns fatores, sobretudo o clima e a rocha matriz. A pesquisa permitiu reconhecer três compartimentos pedogeomorfológicos distintos, descritos a seguir.

\subsection{Compartimento do Argissolo Vermelho Amarelo eutrófico (ex-Podzólico Vermelho Amarelo Eutrófico)}

Trata-se de um compartimento marcado pelas declividades mais acentuadas onde a condição de altitude proporciona desenvolvimento de solos mais profundos que os encontrados na superfície sertaneja, no caso os Argissolos Vermelho Amarelos eutróficos comuns na área próxima ao Riacho Vale do Boqueirão.

De acordo com o sistema brasileiro de classificação de solos da EMBRAPA (1999), essa classe de solo tem profundidade variável, é forte a imperfeitamente drenada, de cores avermelhadas ou amareladas, e mais raramente, brunadas ou acinzentadas. A textura varia de arenosa a argilosa no horizonte A e de média a muito argilosa no horizonte $\mathrm{Bt}$, sempre havendo aumento de argila daquele para este. Compreende solos minerais, não hidromórficos, com horizonte $\mathrm{B}$ textural ou B nítico, com argila de atividade alta e alta saturação por bases, imediatamente abaixo do horizonte A fraco ou moderado, ou horizonte E. Estes solos variam de bem a imperfeitamente drenados, sendo normalmente pouco profundos (60 a $120 \mathrm{~cm}$ ), com sequência de horizontes A, Bt e C, e nítida diferenciação entre os horizontes A e Bt, devido ao contraste de textura, cor e/ou estrutura entre eles. A paisagem abaixo representa a parte significativa da área de estudo (Figura 2)

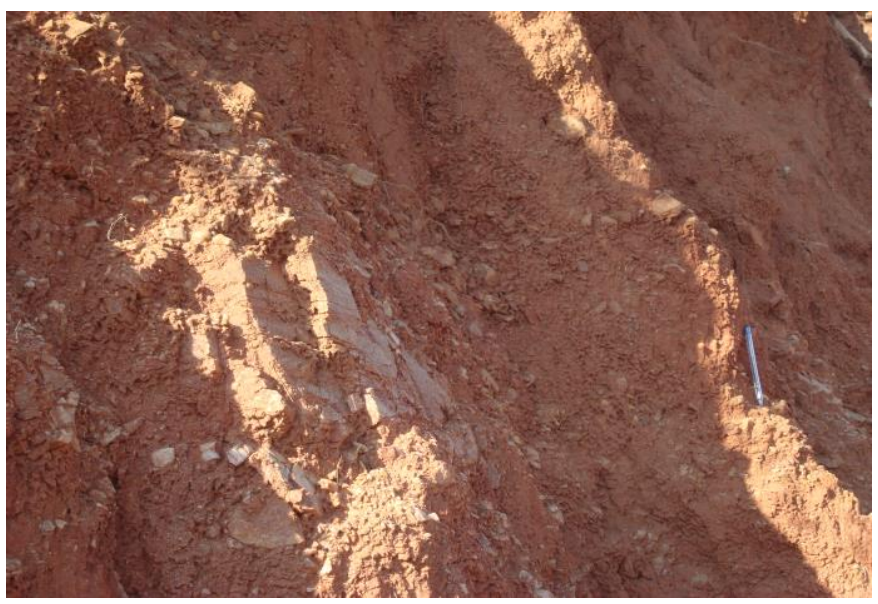

Figura 02. Solos Drenados no Boqueirão. Fonte: Francivanda Dias (2016) 


\section{OS DESAFIOS DA GEOGRAFIA FÍSICA NA FRONTEIRA DO CONHECIMENTO \\ Instituto de Geociências - Unicamp \\ Campinas - SP \\ 28 de Junho à 02 de Julho de 2017}

As práticas agrícolas nesse solo, geralmente estão associadas ao cotidiano da comunidade, com destaque para o cultivo em pequena escala de espécies frutíferas. Mas o manejo é indutor de degradação pelo uso e ocupação do solo.

\subsection{Compartimento do Neossolos Litólicos ( ex-Litossolos)}

Trata-se de um compartimento marcado pela presença de inselbergs. Neles predominam solos rasos, pedregosos, com vegetação arbórea arbustiva, sendo uma característica do bioma caatinga. Em consequência dos solos essa área é pouco utilizada para atividade agrícola por apresentar baixos índices de fertilidade, sofrendo com processos erosivos ocasionados pelo intemperismo químico.

Os solos rasos (profundidade igual ou inferior a $50 \mathrm{~cm}$ ) correspondem a solos com fraca evolução pedogenética, textura arenosa ou média e normalmente cascalhenta, drenagem variando de moderada à acentuada. No geral, apresentam um horizonte A diretamente sobre a rocha $-\mathrm{R}$, ou sobre o horizonte de alteração desta (C). Possuem pedregosidade ou rochosidade na superfície e frequentemente são encontrados associados a afloramentos rochosos. Possuem grandes limitações quanto ao uso agrícola devido a vários fatores como: alta suscetibilidade à erosão, são pedregosos, rochosos, pouca profundidade, falta d'água e aos fortes declives das áreas serranas. São formados a partir de materiais de várias rochas pertencentes a diversas formações geológicas, como gnaisses, granitos, migmatitos, arenitos, folhelhos, entre outras. A Figura 3 mostra a paisagem desses solos.

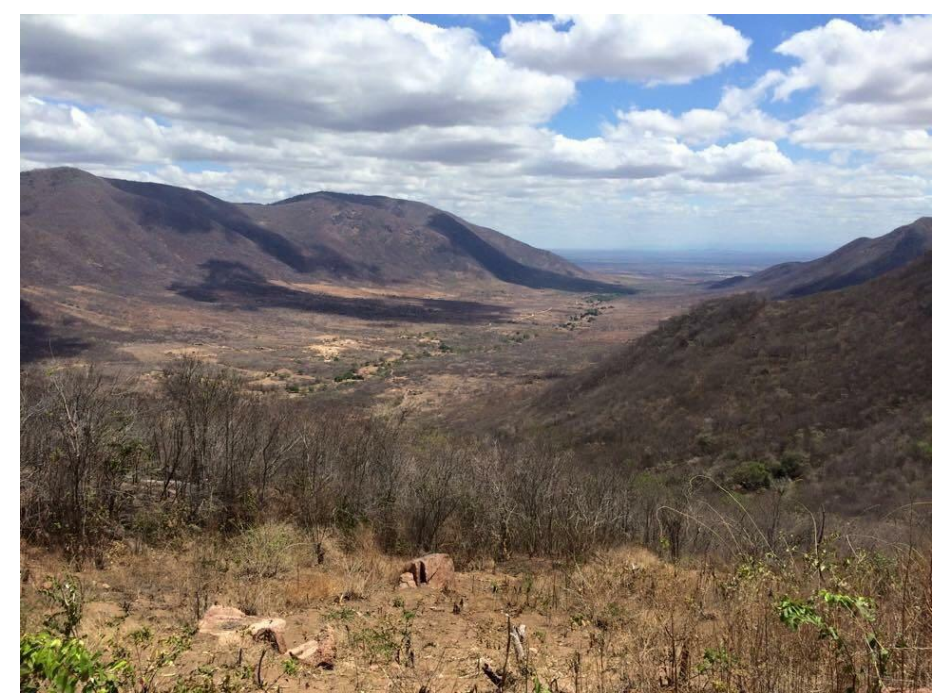

Figura 03. Afloramentos Rochosos no Boqueirão. Fonte: Francivanda Dias (2015) 
XVII Simpósio Brasileiro

de Geografia Fisica Aplicada

I Congresso Nacional

de Geografia Física
OS DESAFIOS DA GEOGRAFIA FÍSICA NA FRONTEIRA DO CONHECIMENTO

Instituto de Geociências - Unicamp

Campinas - SP

28 de Junho à 02 de Julho de 2017

\subsection{Compartimento dos Neossolos Flúvicos (Solos Aluviais)}

Corresponde ao compartimento próximo de cursos de água, que na área estão próximos aos rios da superfície sertaneja e é constituída pelo predomínio de Neossolos Flúvicos que se caracterizam por serem poucos evoluídos, variando de profundos a muito profundos, possuindo um perfil que comumente apresenta um horizonte A sobreposto ao horizonte $\mathrm{C}$, quase sempre composto por várias camadas que se diferenciam principalmente pela textura e granulometria, não guardando entre si, relações genéticas.

Esses solos possuem alta fertilidade natural, por isso são dotados de elevado potencial ao uso agrícola, o que os torna bastante utilizados, inclusive com sistemas de irrigação. Apresentam textura arenosa e siltosa, com variações de proporcionais de argila dentro de seus perfis. Por sua fertilidade e relevo plano estes solos destinam-se ao desenvolvimento de práticas agrícolas no ambiente semiárido, predominando a agricultura de subsistência. Conforme a figura 4, observamos o uso agrícola do solo.

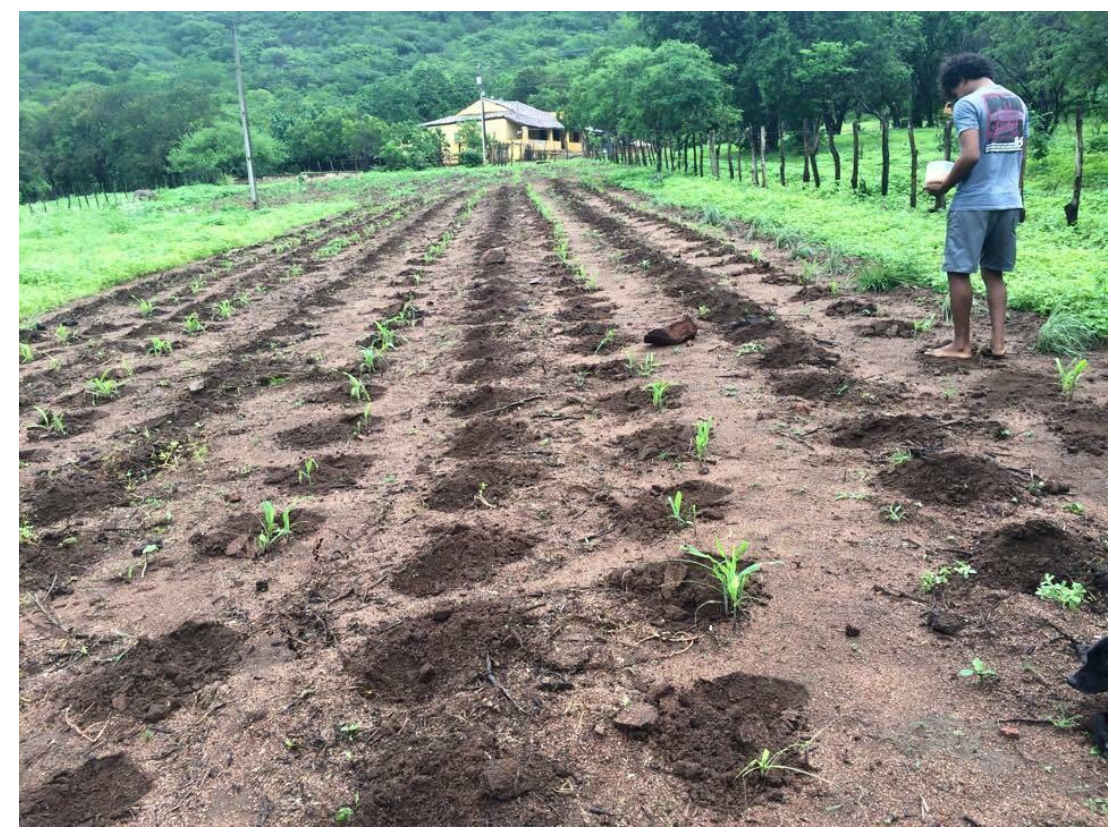

Figura 04. Prática Agrícola no Boqueirão. Fonte: Francivanda Dias (2015)

A Partir da imagem, pode-se observar a prática agrícola desenvolvida, no caso pela maioria da população residente na comunidade Boqueirão, sobre relevo plano ou suavemente ondulado possibilitando o acúmulo de água para as plantas não sendo suscetíveis à erosão. Porém, vale mencionar que estas práticas agrícolas são generalizadas na área, mesmo em relevo de declividade acentuada. A mesma está intimamente atrelada à questão social e agrária do Nordeste semiárido. 
Nesse sentido, esse tipo de paisagem representa a dinâmica do ambiente semiárido e constitui uma questão natural e social, marcada pela agricultura familiar.

\section{Considerações Finais}

Diante das informações apresentadas, os tipos de solos apresentam um relativo potencial que pode ser aproveitado tanto para a agricultura quanto a pecuária local, desde que haja a implementação de técnicas adequadas, principalmente nas unidades que apresentem ocorrência de concreções e relevos com declividades relativamente acentuadas, a exemplo principalmente dos Argissolos, que ocorrem em relevos mais ondulado.

Quanto a relação pedogeomorfológica a mesma tende a inibir as atividades antrópicas moldando a paisagem, e inferindo um tipo de modificação no ambiente local, favorecidas mais pelos tipos de solos, por possibilitarem o desenvolvimento das atividades agrícolas de subsistência, que são representativas do contexto cultural da paisagem semiárida.

\section{Referências}

AB'SABER, A. N. Um conceito de geomorfologia a serviço das pesquisas sobre o Quaternário. 1969. n. 18. Geomorfologia.

ARAÚJO, G. H. de S. (2005). Gestão ambiental de áreas degradadas. Rio de Janeiro: Bertrand Brasil. CHRISTOFOLETTI, A. Aplicabilidade do conhecimento geomorfológico nos projetos de planejamento. In:GUERRA, A. J. T.; CUNHA, S. B. Geomorfologia -2a ed. - São Paulo: Editora Blucher, 1980, p. 102-110.

DePartamento De SOlos. Conteúdos Básicos De Geologia E Pedologia Para As Disciplinas De Sol 213, Sol 215 E Sol 220. Viçosa - Minas Gerais, 2005.

EMPRESA BRASILEIRA DE PESQUISAS AGROPECUÁRIAS/EMBRAPA. Centro Nacional de Pesquisa de Solos. Sistema brasileiro de classificação de solos. Rio de Janeiro, 1999.

FALCÃO SOBRINHO, J; FALCÃO C. L. C. Práticas agrícolas inadequadas acentuam processo erosivo na Serra da Meruoca. R. Ci. e Téc., Fortaleza, ano 3, n. 3, dez./2001.

LIMA, E. C. Análise geoambiental do Vale do Riacho Boqueirão - Sobral/CE. Revista Homem, Tempo e Espaço. Sobral (CE), setembro de 2007.

RADAMBRASIL - Folhas SA. 23/24 - Fortaleza - Brasil, MME, Levantamento de Recursos Naturais, Vol.21, 1981.

SOUZA, M. J. N. Bases Naturais e Esboço de Zoneamento Geoambiental do Estado do Ceará. Contexto

Geoambiental do Semiárido do Ceará: Problemas Perspectivas. In: Semi-Árido: Diversidades, Fragilidades e

Potencialidades., Sobral: Sobral Gráfica, 2006.

SUPERINTENDÊNCIA DE DESENVOLVIMENTO DO NORDESTE - SUDENE/EMBRAPA/ CEARÁ. Levantamento exploratório: reconhecimento de solos do Estado do Ceará. Recife:, 1973. ( Bol. Téc. 28, Série pedológica, 16 